\title{
Burdens, Sludge, Ordeals, Red Tape, Oh My! A User's Guide to the Study of Frictions
}

\author{
Jonas Krogh Madsen, Roskilde University, \\ Kim Sass Mikkelsen, Roskilde University \\ Donald Moynihan, Georgetown University
}

\begin{abstract}
Recent years has seen dramatic growth to the study of frictions that individuals experience, especially in their interactions with the public sector, creating both the potential for new research opportunities and conceptual confusion. We seek to head off the latter by providing, in one place, a definition, description of the development, and comparison of four dominant conceptions of frictions: ordeal mechanisms, red tape, administrative burden, and sludge. In particular, we discuss the four concepts' definition and use in terms of their objectivity, distributive effects, object and domain, and deliberate design. The paper helps researchers to understand the overlap and distinctions between these concepts, and the role of public administration in these different traditions. Comparisons of the different approaches' thinking also suggest opportunities for mutual learning.
\end{abstract}

Pre-publication version of manuscript accepted in Public Administration, https://doi.org/10.1111/padm.12717

Keywords: Red Tape, Administrative Burden, Sludge, Ordeal Mechanisms, Frictions

Acknowledgements: we are grateful to the following who provided constructive feedback on earlier versions of this manuscript: Mary Feeney, Pamela Herd, Wesley Kaufmann, Lars Tummers, Sanjay Pandey, Cass Sunstein, and the anonymous reviewers of Public Administration. 


\section{Introduction}

In recent years, it has become increasingly popular to study how citizens and public employees experience frictions in the delivery of public services. Frictions help us understand how well, and legitimately, governments do their job, and are most often addressed through concepts such as red tape and ordeal mechanisms, and - more recently - administrative burden and sludge (Carrigan, Pandey, \& Van Ryzin, 2020; Sunstein, 2020).

With this multitude of concepts - and one could include more - the study of frictions is potentially hampered by conceptual clutter that challenges the accumulation of knowledge. ${ }^{1}$ Some researchers appear to be using differing concepts interchangeably (e.g. Steijn \& van der Voet, 2019) while others contrast them and find some less useful than others for their research agendas (e.g. Heinrich, 2016; Peeters \& Widlak, 2018). Certainly, there are similarities that provide a basis for sharing of research and ideas across fields of studies. But the four concepts are not equivalent. They feature significant differences in definitions and underlying assumptions. Such basic differences meaningfully alter how researchers approach the topic, affecting both the basics of how they measure key variables and the types of explanations they pursue. This combination of overlap and substantive differences may cause researchers studying quite different phenomena to be incorrectly grouped together. And it may cause researchers studying similar phenomena to fail to communicate, or set up rival camps rather than coordinating efforts and learning from one another.

It is therefore an opportune time to undertake a conceptual stock-take of the study of frictions. In this article, we map out the conceptual landscape to not just provide a user's guide to a growing,

\footnotetext{
${ }^{1}$ We do not mean for frictions to join the existing pool of concepts but use it simply as a convenient linguistic shorthand to refer to the four concepts we discuss.
} 
interdisciplinary attention to the broad topic of what we refer to as frictions, but to also address three basic questions of interest to public administration scholars and other researchers: How are administrative burdens, red tape, ordeals, and sludge similar? How do they differ? How might researchers studying them learn from one another?

As public administration scholars, we focus the greatest part of our energy in the "home-grown" concepts of red tape and administrative burden, searching systematically through their associated literatures. $^{2}$ We also examine sludge and ordeal mechanisms more briefly as useful contrasts for lesson-drawing beyond the field. The four concepts do not form an exhaustive list. On the contrary, as with any relatively broad social science concept, there are other potential constructs we could have pursued. Some, such as formalization or transaction costs, do address potential frictions but are too broadly conceptualized for our purposes of studying frictions within public services.

To secure the foundation of our discussion, we review relevant literature. Yet, the purpose of our paper is not a systematic review. Instead, our focus is conceptual discussion and clarification. As a result, we do not provide exhaustive overviews of the empirical literatures on any of our four types of frictions, but focus instead on papers that provide the conceptual foundations, and investigate how they are alike, how they differ, and what their similarities and differences teach us about them.

\footnotetext{
${ }^{2}$ To identify the literatures, we searched the Journal of Public Administration and Theory, Public Administration Review, Public Administration, Governance, and Public Management Review from 2012 to 2020 for "red tape" and "administrative burden" in either title or abstract and added well-known or well cited papers to this list. Prior to 2012, we rely on Bozeman and Feeney's (2011) exhaustive review of the red tape literature. For administrative burden, our search returned only a few sources, making it necessary to supplement with exhaustive reviews of all published papers citing either Burden, Canon, Mayer, and Moynihan (2012), Herd and Moynihan (2018), or Moynihan, Herd, and Harvey (2014). The appendix contains a complete list of reviewed papers and books. For "sludge" we focus on the only published papers that present the concept, and for ordeal mechanisms, we draw heavily on Nichols \& Zeckhauser's (1982) canonical introduction of the concept, and Zeckhauser's recent review (2020).
} 
Our basic criterion for inclusion is, therefore, to focus on papers that develop one of the four types of concepts in public services that public administration scholars are likely to be exposed to. In doing so, we aim to not only bring attention to other conceptualizations of frictions outside of public administration, but also highlight the overall contribution that public administration has made to the framing of frictions relative to neighboring fields.

We start out by outlining definitions, and discuss how they differ. We then analyze similarities and differences between the concepts along four parameters: Whether the concepts describe objectively existing or subjectively experienced phenomena (objectivity); whether they facilitate more targeted provision of public services or inequality (distributiveness); who is typically analyzed as the object and in what setting (object and domain); and to what extent the concepts theorize frictions as deliberately imposed on their objects (intentionality).

The four parameters are chosen for their capacity to comparatively illustrate similarities and differences between concepts. As such, our choice of parameters is inductive, and not deductive, an inevitable function of trying to make sense of overlapping concepts, some relatively novel, without pre-determined hypotheses about them. Our guiding framework is based on addressing the questions mentioned above, exploring similarity, thematic divergence, and in the process drawing lessons and identifying internal contradictions.

In doing so, we draw some notable implications. One is that the recent work on frictions is expanding the purview of public administration to consider how members of the public experiences the state, as opposed to focusing on the experiences of public employees and managers. Second, there is much possible overlap between the approaches. Some of this overlap is revealed in contradictions between formal concept definition and actual research practice. For example, while red tape is generally 
defined in terms of rules, it usually focuses on individual experience. Another example is that both red tape and ordeals literatures define frictions solely in negative terms, reflecting a very general evaluative standard, but the sheer difficulty of identifying rules that in practice are inherently negative should motivate studies to acknowledge the potential benefits of frictions relative to their costs. The focus on frictions without benefits may blind researchers from addressing frictions where benefits exist but do not exceed costs, or where costs more than justify the friction. Finally, despite the potential for overlap, there are some real differences. For example, the ordeals approach assumption that rational actors will weigh the costs and benefit of hassles is at odds with the administrative burden emphasis on human capital differences, which implies that frictions have a disproportionate negative effect on those with fewest resources.

We start with the following assumptions to demarcate our topics. Ordeal mechanisms emerge from the study of economics in the early 1980s as a way to understand how public services might be targeted (Nichols \& Zeckhauser, 1982). The study of red tape finds its modern origins as a topic of empirical study in public administration research in the early 1990s (Bozeman, 1993), though was widely debated before then. Administrative burden, as we describe it here, mixes public administration and policy studies, and is more recent (Herd, Deleire, Harvey \& Moynihan, 2013). The most recent conceptual newcomer, sludge, is articulated first by Richard Thaler in 2018, expanded upon by Sunstein $(2019,2020)$, and extends Thaler and Sunstein's earlier joint work on nudges (2008).

We do not advocate for any particular approach to frictions or claim that the included concepts or parameters of debate exhaust all possibilities. Our goals are more modest: to compare a set of related 
concepts to explain distinctions and offer some implications for learning. With that, let us begin at the only place where such discussions can begin: with definitions.

\section{Definitions}

Table 1 details in alphabetical order the definitions commonly used in each approach. To help sort through the definitions, we add clarifying labels largely of our own devising.

[Table 1 around here]

Starting off at the top of table 1, the administrative burden definition of Burden et al. (2012), and Herd and Moynihan (2018) is the most widely used in this nascent literature. We refer to this as the experience definition. The definition is comparatively simple. All it requires is "an individual" - who can be either a citizen or an administrator (Burden et al., 2012, p. 741) - experiencing the implementation of a policy as "onerous." The individual is the main object of the definition, not the burden. Moreover, the evaluative standard of the burden - what we will refer to below as the "locus of evaluation" - reflects back on the individual, not on policy goals, organizational purposes, evaluations of any designated stakeholders, or the public as a collective. This, we will argue, is an important difference between the experience definition and the definition of other concepts. The impositions definition (Heinrich, 2018) conceives of burdens as onerous demands imposed on entities in their interaction with government. The most important difference to the experience definition is the shift in main character from the individual to the burden itself, which moves it closer to the ordeal mechanism and sludge definitions discussed shortly. 
An important supplement to the simple experience definition comes with Herd, DeLeire, Harvey, and Moynihan (2013), and Moynihan, Herd, and Harvey (2014), who present burdens as comprised of three types of costs: the time and effort in finding out about public services and conditions (learning costs), the effort and financial costs spent on completing forms, accessing services, or responding to administrative demands (compliance costs), and stigma, stress, and autonomy loss arising from interactions with the state (psychological costs).

The definition of ordeals comes from the original paper outlining the concept and a recent review, both featuring Richard Zeckhauser. There are similarities to particularly the impositions definition of administrative burden but it is also distinguished by the idea that ordeals constitute deadweight loss to the user. We return to some conceptual difficulties this creates later. Sludge is articulated briefly in Thaler (2018) and then in greater detail by Sunstein $(2019,2020)$, is defined as frustrating the direction or goal that an individual seeks.

As shown in table 1, the long history of red tape research in public administration furnishes a wide selection of definitions, though early work avoided operational definitions (e.g. Kaufman, 1977). Among the most common definitions is Bozeman's 'rules, regulations and procedures that entail a compliance burden without advancing the legitimate purposes they were intended to serve' (2000, p. 12). ${ }^{3}$ We refer to it as the legitimate purposes definition. An earlier, and widely used, organizational definition (Bozeman, 1993) is similar but refers to the function that rules serve for the organization (their "functional object") rather than their intended purposes. Bozeman (1993; 2000; 2012) also introduced the less frequently used stakeholder definition and the related multidimensional definition of red tape (the latter not shown in table 1). While both share similarities with the legitimate purpose

\footnotetext{
${ }^{3}$ Bozeman's definition is still used in studies of red tape today (e.g. Tummers, Weske, Bouwman, \& Grimmelikhuijsen, 2016; Kaufmann \& Tummers, 2017).
} 
definition, they differ on their referents (their "locus of evaluation"). The former refers to costs to “objective values by a given stakeholder group” (Bozeman, 1993, p. 284). The latter introduces the notion that red tape is evaluated by "designated stakeholders" but perceives it as a balance of costs and benefits rather than a rule that these stakeholders view as serving no purpose whatsoever (Bozeman, 2012, p. 257).

These definitions share the idea that red tape frustrates functional objects, interests, or purposes being served. However, a different strand of red tape research puts the emphasis on employee or managerial perceptions. Specifically, in what we call the impressions definition in table 1, Pandey and Kingsley define red tape as "impressions on the part of managers that formalization (in the form of burdensome rules and regulations) is detrimental to the organization" (2000, p. 782). In many respects, this definition best mirrors how empirical scholars have used the concept; as hassles that employees and managers perceive in their job (cf. Kaufmann \& Haans, 2020). Similarly, Van Loon, Leisink, Knies, and Brewer's (2016) job-centered red tape definition (not shown in Table 1) explicitly targets impressions of compliance costs and lack of functionality. Similar to administrative burden, these perception-centered definitions place individuals at the locus of evaluating frictions in ways that other red tape definitions do not. Unlike administrative burden, however, the evaluative dimension refers to what the individual deems beneficial, detrimental, or functional for the organization (impressions) or their job (job-centered); not what the individual deems personally onerous.

\section{Parameters}

We next build from the definitions and the conventions of research in these areas to identify basic parameters of distinction and emphasize similarities and differences between the constructs. The list of parameters is clearly non-exhaustive. However, it illuminates some core questions that may aid the 
mutual learning in the study of frictions. Table 2 offers a simplified preview of what follows. We do not give each concept equal attention, or address them in a consistent order - instead, we organize the discussion around predominant areas of conflict or overlap.

[Table 2 around here]

\section{Objectivity}

Our starting point is the question of objectivity. Is red tape objectively red tape? Are administrative burdens objectively onerous? Such questions relate to both conceptual understanding and measurement. Particularly for the more subjectively oriented conceptions, the question of locus of evaluation emerges: Who determines whether frictions are onerous (administrative burden), advance their purpose (red tape), or are excessive and unjustified (sludge)? Assumptions of the locus of evaluations are embedded in all four concepts.

Administrative burdens are first and foremost experienced: "the state can construct rules and processes that give rise to the experience of burden, but the individual experience of burden is distinct from rules and process" (Herd \& Moynihan, 2018, p. 22). It is easy then, but incorrect, to assume that experiences are inherently and exclusively subjective. To be sure, one way of examining burdens is to ask people about their experiences. For psychological costs in particular, there may be few alternatives (though see Hattke, Hensel, \& Kalucza 2020).

The concept of administrative burdens is broad enough to allow both objective measures of experience, as well as measures that capture subjective interpretation of that experience. An example: Two people forced to wait one hour at an office can objectively have experienced the same compliance costs. Yet, the two individuals might interpret that experience differently - for example, 
the person trying to manage two small children might experience greater stress than their childless counterpart. Such interpretative differences are relevant, and likely to be reflected in questions about psychological costs. However, objective indicators of time, cost, and effort can be used to measure frictions generally, and the experience of compliance costs in particular, such as "objective measures of delays such as length of time to process applications, or wait times at offices" as well as number of enrollment questions, documentation required, or financial costs (Herd \& Moynihan 2018, p. 257). Moynihan, Herd, and Ribgy (2016) illustrate such a technique by coding administrative forms, calculating the difficulty an individual would have in completing the form based on the number of questions, documentation demands and language complexity embedded in the process. It is therefore reasonable to assume that while there will be variation in the experience of frictions, and while subjective measures capturing this variation are useful, there are ways to capture experiences of burdens that rely on objective measures.

For red tape, the answer to the objectivity question varies across definitions. To the proponents of the stakeholder, multidimensional, impression, and job-centered definitions, red tape might not be red tape objectively as even perfectly legitimate and effective rules can be viewed as cumbersome and pointless by relevant stakeholders. Conversely, rules without organizational purpose can avoid being red tape if relevant stakeholders perceive them as favoring their job-related values (e.g. Van Loon et al., 2016). More broadly, the literature is split into a typically older branch studying rules and a newer branch studying perceptions of rules (e.g. Pandey \& Scott, 2002; Bozeman \& Feeney, 2011). Similar to administrative burden, of course, the two should be related: Red tape cannot have effects unless it is experienced as red tape to stakeholders, thereby giving life to the effects (cf. Kaufmann \& Feeney, 2012). For these reasons, much current red tape research does not in practice consider its subject objectively given, in "sharp contrast" (Carrigan et al. 2020, p. 47) to widely used definitions - 
particularly the organizational and legitimate purposes definitions - that denote objectively illegitimate and pointless frictions.

The ordeal mechanisms literature and work that examines sludge generally avoid self-reports of people's experience, and instead rely on objective changes in rules, requirements, or demands posed on people, preferably driven by exogenous shocks, changes, or spatial differences. Thus, for example, Deshpande and Li (2019) examine Social Security field office closures as an indicator of ordeals (an objective increase in demands), while tracking heterogeneous effects on people with different levels of economic circumstances and health. Their study offers a model for how objective indicators can document whether different groups - as reflected by socioeconomic differences - are more exposed to or impacted by frictions than others. The locus of evaluation in both literatures appears to be at the individual level. Ordeals see frictions as an individual "deadweight loss." (Zeckhauser, 2019, p. 1), but simultaneously assume it to be socially useful in its capacity to ensure efficient targeting of services. Similarly, sludge is characterized by frustrating individuals who encounter it without offering offsetting benefits to them (Sunstein, 2020, p. 7), yet elsewhere - with a different locus of evaluation - Sunstein states that the social positives and negatives of sludge should be balanced up against each other (Sunstein 2019, p. 1850). Sludge may be sludge for the common good even if it frustrates individuals.

In contrast, administrative burden is clear about the locus of evaluation, placing it upon the individual. Indeed, burdens are costs to the subjects experiencing them - as the concept's core definition suggests. Whether they are beneficial or detrimental from the perspective of the collective is an entirely separate empirical question. Nevertheless, administrative burden shares with sludge the idea that frictions may be justified when viewed from a social lens (see Linos, Quan \& Kirkman, 2020). 
In sum, we have some convergence between the different literatures concerning objectivity, but one not easy to match with the definitions. Much of the red tape literature is based on subjective assessments, even as the objectively oriented organizational and legitimate purposes definitions are still popular. Despite this tension, for scholars interested in subjective assessments, the red tape literature has gone far in terms of building and fine-tuning high-quality measures of perceived red tape (e.g. Coursey \& Pandey, 2007; van Loon et al., 2016). This empirical practice echoes rather than contradicts the definition of administrative burden to focus on individual experience as distinct from - but related to - actual rules and process. Some of the potential convergence emerges from more recent behavioral approaches, which often employ experimental designs, and an examination of behavioral responses, such as take-up (e.g., Braconnier, Dormagen, \& Pons, 2017, Yasenov, Hotard, Lawrence, Hainmueller, \& Laitin, 2019). As the literatures stand, despite differences in emphasis in locus of evaluation, the objectivity of frictions does not create a hard distinction between how the concepts are or could be utilized and measured in practice.

\section{Distributiveness}

An extension of the notion that individuals' experiences with friction may vary is the socially distributive outcomes that result from such variation. Here, distributiveness describes how frictions affect the distribution of services, and, by extension, reduce or reinforce existing patterns of inequality.

Given its focus on public employees (see below), the red tape literature investigates a fairly homogenous population, and therefore seldom address questions of distributive effects of frictions. By contrast, the potential for distributive effects is prominent in the administrative burden, ordeal mechanisms, and sludge literatures, but with distinct perspectives and to varying degrees. 
The clearest dividing line comes between the administrative burden and ordeal mechanism perspectives. The ordeal mechanism approach argues that utility drives people's willingness to forego goods:

"The artist who is a child of affluent parents may opt not to go through tedious procedures to get food stamps; the doctor may decide not to fill out forms if the value of the procedure to the patient is not worth the administrative burden; an incapacitated individual with an at-home caregiver may receive more comfortable but much less subsidized home care; and a middle class individual may steer clear of any stigma from care at the free-clinic" (Zeckhauser, 2019, p. 2).

Accepting the notion that the well-resourced avoid the hassles of receiving benefits because they have less need allows the ordeals approach to assume that frictions act as a useful tool for targeting limited resources to those that need them most. More efficient allocation of resources thereby become the presumed indirect social benefits of ordeals.

The administrative burden framework relies on different assumptions. First, it argues that the political economy of the distribution of goods means that the neediest are often most targeted by burdens. The poorest face means-tested programs, and street-level bureaucrats may further discriminate against disadvantaged groups (Nisar, 2018). Second, there are human capital differences: people with lower cognitive and noncognitive skills will struggle more with burdens, even as they may be most in need of the benefits public programs provide (Christensen, Aarøe, Baekgaard, Herd, \& Moynihan, 2020). Unlike the ordeals approach, these two assumptions suggest that frictions are not an efficient means of sorting on need, but instead most hurt disadvantaged groups. Sunstein (2019, p. 1872) echoes this point, noting both the rationing logic of ordeal mechanisms, but pointing out the inefficiency of sludge for targeting. 
The distributive effects of burdens is ultimately an empirical question. However, starting with an ordeals or administrative burden approach may structure and guide how an analysis is designed to test these competing assumptions. For policymakers looking to target services, the administrative burden framework offers little direct guidance other than to suggest that using frictions is an inefficient way of doing so. Starting with an ordeal mechanism framework, by contrast, focuses the analysis less on inequality and more on whether service is claimed by groups who may not need it (Alatas et al., 2016).

Taken together, the notion of distributive effects vary across the different concepts. Barely touched upon in the red tape literature due to its empirical focus, administrative burden, ordeal mechanisms, and sludge predict heterogeneous effects, yet with considerable differences. Ordeal mechanism researchers may benefit from considering the political economy and human capital causal mechanisms outlined in the administrative burden and sludge frameworks.

\section{Object and Domain}

Who is the object of onerous, detrimental, pointless, or irritating frictions? The object is conceptually relevant as the red tape and administrative burden literatures seem relatively differentiated on the relationship between frictions and their object (e.g. Heinrich, 2016; Peeters, 2020). A related question is what is the domain or sector within which these objects operate? Is it the public or private sector or both?

Studies of sludge and ordeal mechanisms overwhelmingly focus on members of the public. Most studies of administrative burden do the same, with some exceptions (e.g., Burden et al., 2012; Lavertu, Lewis, \& Moynihan, 2013; Linos \& Riesch, 2020). For example, implementing burdens may have a negative effect upon employees' motivation (Herd \& Moynihan, 2018, p. 32-33). Conversely, 
the object of red tape in the literature has overwhelmingly been public servants and managers (Bozeman \& Feeney, 2011). Indeed, Peeters (2020, p. 567) argues that a key distinction between administrative burdens and red tape is that the former focuses on citizen's experience, while the latter is primarily focused on "paperwork and regulations that affect bureaucrat's work." (see also Heinrich 2016). Again, exceptions exist, where red tape is used to study citizens, firms, or countries (e.g. Tummers et al., 2016; Kaufmann \& Tummers, 2018; De Jong \& Witteloostuijn, 2015; Kaufmann, Hooghiemstra, \& Feeney, 2018).

In practice, a division of labor between red tape and administrative burden may be emerging in terms of the objects they study. The division of labor is not solely a matter of self-organization, but may reflect a path dependency in how researchers develop concepts to fit certain needs. The administrative burden framework can be seen as a project to focus public administration scholarship toward citizenstate interactions in a way that red tape work had not. Moynihan and Herd (2010) originally used red tape theory - and the legitimate purposes definition - to study the impact of rules and regulation on democratic rights and participation. However, they concluded that red tape's focus on public employees' experience of frictions had overlooked policy feedback processes central to citizen-state relations. Such inattention to citizen experiences caused the field of public administration more broadly to exclude "what should be core questions" (2010, p. 657), necessitating a novel conceptual framework in the form of administrative burden. Yet this does not mean that red tape cannot have citizens as its object, nor that administrative burdens cannot study public managers or employees.

Another related aspect to how scholars work with frictions is the domain in which they occur. Here, definitional practices and research customs both offer insights, though they might be ultimately misleading. For red tape, the definition does not specify public or private settings, but the research customs have been to overwhelmingly situate it in public domains with the exception of studies 
comparing red tape across public, private, and non-profit organizations (e.g. Feeney \& Rainey, 2009; Pandey \& Kingsley, 2000). Ordeal mechanisms are also primarily situated in the domain of healthcare or other public services. Sludge is explicitly applicable in both public and private settings, including customers receiving purely private services (Sunstein, 2019). Administrative burdens presents itself as related to public policy implementation, but includes private actors who help implement policies or mitigate burdens. Some authors have pushed the application of the concept. For example, Carter, Scott, and Mahallati (2018) use it in the nonprofit domain, where the object is voluntary environmental programs.

\section{Intentionality}

By looking at the intentionality of frictions, we raise the question of how they come about. Do frictions "just happen" as policies and organizations develop over time or are they deliberately imposed on stakeholders? A novelty of the administrative burden framework is to characterize burdens as a form of policymaking 'by other means' (Herd \& Moynihan, 2018). Red tape scholarship, by contrast, has largely not pursued questions of political intentionality in the creation of frictions (Bozeman \& Feeney, 2011). Different approaches therefore emphasize different potential sources of frictions, but these sources are generally not mutually exclusive.

For example, Herd and Moynihan (2018) illustrate how policy actors use burdens to limit access both to constitutional rights such as voting, and welfare and health services. Heinrich (2018) details how policymakers use burdens to exclude immigrants from public services in Texas. Finally, Baekgaard, Moynihan, and Thomsen (2020) find that policymakers' willingness to support burdens in the welfare system depend on their own personal experiences with the welfare system, ideology, and perception of welfare claimants' deservingness. Accepting the potential intentionality of burdens makes it easier 
to grasp the puzzling paradox why they remain despite a broad interest in removing them. Simultaneously, it allows normative discussions on the legitimacy of burdens and the question of who should shoulder them if they prove impossible to eradicate. The deliberate imposition of burdens also points to the possibility that burdens can be intentionally reduced or removed, by, for example, targeted outreach of information, simplification of forms or other formal processes, or using information technology. Of course, the attentiveness of administrative burden research to political origins does not mean all burdens are intentionally imposed. Rather, burdens can have intentional origins both in and outside politics, as well as be unintended by-products of political negotiations, complex systems, or organizational change (Peeters, 2020).

The literature on sludge readily acknowledges that sludge may be the product of intentional action (Thaler, 2018; Sunstein, 2019; 2020), or accumulate over time as a result of the bounded rationality of institutional designers (Shahab \& Lades, 2020). Ordeals are also constructed, but the product of a rational and enlightened principal seeking to maximize social welfare with limited resources; "to direct care to those who will benefit from it the most" (Zeckhauser, 2019, p. 3). The ordeal serves to reveal information on who those people are, and to better serve them. Thus, ordeals are intentional, but with a positive social goal. There is little consideration that the principal might be acting from ideological interests, or at odds with the best interests of the population, although Zeckhauser (2019) does acknowledge the possibility of rent-seeking by actors "who enjoy the current arrangements and by the disproportionate influence of entities that are already in place.” (2019, p. 26)

In the classic red tape literature, politics and the quest for gaining political control and avoiding blame are seen as an important determinant of red tape (e.g. Kaufman, 1977; Bozeman, 1993; 2000). However, the dominant focus has been on organizational sources of red tape, such as rules that once serve a useful function becoming outdated (Bozeman \& Feeney 2011). When red tape researchers 
have studied issues of control, they have largely focused on "managerial over-control" that can easily be perceived as red tape by subordinates (e.g. Kaufmann, Borry, \& DeHart-Davis, 2019). Otherwise, they have looked at non-political origins of red tape, though these may themselves, of course, originate with policy. To give an example: Brewer and Walker (2010) argue that public service professionals and employees in organizations more exposed to marketization are more likely to perceive rules to be red tape. One partial exception is Kaufmann et al. (2018) who consider political incentives as a link between rule enforcement, federalism, government ideology, and red tape (see also Bozeman \& Anderson, 2016).

Some frictions are rooted in politics, while others have roots in more mundane organizational dynamics. While not going as far to present red tape as policymaking by other means, parts of the red tape literature acknowledge the idea that frictions arise from a political environment, with politics being one source of bureaucratic pathologies. Yet literatures on other frictions, notably administrative burden, are more attuned - including in empirical studies - to how the impositions of burdens can be a political process. Regardless whether they are a function of deliberate action, frictions are still a function of political and administrative choices, including choices not made.

\section{Discussion}

What have we learned from comparing the different conceptualizations of frictions? We first consider overlaps between the concepts, which are partly revealed by internal contradictions between how the concepts are defined and how they are used in practice. Collectively, this reveals areas of potential overlap, though these are largely unrealized. We also point to continuing areas of tension across the different approaches. 


\section{How are the Concepts (Potentially) the Same?}

In returning to our first question, we observe a number of existing overlaps in underlying definitions. Perhaps surprisingly, much of the differences between conceptual approaches are not only rooted in definitions but also the research customs and assumptions with which the concepts are applied in practice.

First, all four concepts usually place the individual (rather than the organization) as the central unit of analysis, as the object of frictions. At the very least, to take effect, frictions have to be experienced by an individual. Moreover, all approaches describe frictions as onerous or costly to their object. The idea of individual experience is, of course, central to the definition of administrative burden. But all definitions of red tape we have discussed also either connote a "compliance burden" (legitimate purposes, organizational, stakeholder, multidimensional) or that rules be perceived as "burdensome" (impressions, job centered) that ultimately must be dealt with by individuals. Similarly, it is individuals who face the, to them, unwelcome frictions described as sludge and ordeal mechanisms.

Second, research custom has established some differences in the objects and domain studied. However, no conceptual hindrances prevent administrative burdens research from having public servants as its objects. Similarly, nothing stops red tape research from choosing objects other than public servants. Red tape, ordeals, and administrative burden all concentrate on public sector examples, though with plenty of examples of private actors delivering those services. The framing of sludge is the broadest in terms of domain, incorporating private practices such as mail-in rebates as well as take-up of public programs. Ultimately, there are no inherent conceptual constraints limiting the concepts to public employees and citizens, respectively, or public or private domains. While the 
literatures we discuss are more focused on public sector frictions, they can easily move beyond these domains to the non-profit or private spheres, which seem especially relevant for researchers interested in non-governmental actors and policy tools for delivering public services. The differences are largely a function of the research interests and training of those using the concepts originally, which over time coheres into an identifiable set of research topic that sets the agenda for new researchers.

Finally, in terms of intentionality, it seems clear that different explanations of the sources of frictions in public services are largely complementary, rather than competing. For example, red tape researchers might take a note from the administrative burden framework to consider how some rules were deliberately designed to generate political, or even partisan, outcomes. By the same token, it would be a mistake for administrative burden, sludge, and ordeals researchers to ignore how basic bureaucratic pathologies of the type highlighted in red tape research play a role in generating frictions. Recent work by Peeters (2020) recognizes this point, focusing on the organizational base of burdens. Peeters suggests that a useful way of understanding the origins of burdens is to organize them using the variables of formal and intentional. This reveals some origins that have seen less attention. For example, burdens which are formal and intentional in origin are "system architecture", standardized systems such as databases, which can pose as well as remove onerous demands (for an illustration of burdens originating in system architecture, see Peeters and Widlak, 2018). Burdens that are informal and imposed intentionally can include corrupt behavior and coping mechanisms by street level bureaucrats. While some of these informal behaviors have received much scholarly attention - there is a large literature on corruption, for instance - thinking about them as frictions open up avenues for research which are certainly worth pursuing, not least since the classic red tape literature has tended to focus on cumbersome formal rules (Peeters, 2020). 


\section{Internal Contradictions Reveal Overlap}

Another way to engage in lesson learning is to examine how our comparative view across concepts reveals internal contradictions within concepts. By internal contradictions, we mean differences between claims inherent in the definition and practice of using the concept for research. Here, our intent is not to criticize any particular approach, and we acknowledge that later approaches have the benefit of observing these contradictions (while not being completely immune themselves). Rather, we believe that doing so highlights further potential areas of overlap.

For both red tape and ordeals, a primary contradiction is between classic definitions that frame their frictions of interest as having no redeeming value, which is clearly contradicted by empirical work. Most red tape definitions contain a notion of inherent negativity of frictions as it does not advance "legitimate purposes" (legitimate purposes); it has "no efficacy" for its functional object (organizational); it serves "no objective" (stakeholder and multidimensional); it is "detrimental to the organization" (impressions); or it is "not helpful" (job-centered). Yet red tape does not have offsetting social benefits and the debate about whether red tape can serve a purpose goes on (Kaufmann \& Tummers, 2018). But empirical studies of red tape have not enforced the strict definitions operationally (Kaufmann \& Feeney, 2011; Pandey \& Scott, 2002; Pandey, Coursey, \& Moynihan, 2007). Pandey and Kingsley’s (2000) impressions definition, Bozeman's (2012) multidimensional definition, and Van Loon's (2016) job centered definition move away from the assumption that red tape has no benefit from any locus of evaluation, by centering the cost on the individual experiencing those costs.

By definition, ordeals conceptualize frictions as a "deadweight loss" yielding "no direct benefits to others" (Zeckhauser, 2019, p. 1-2). This creates a contradiction that bedevils the ordeal mechanism concept: ordeals are assumed to be both negative, but also (indirectly) useful in at least one respect: 
efficient targeting of services to the needy most willing to endure frictions to access services. Whether ordeals actually generate efficient targeting of services is a separate empirical question. Our point is simpler: if ordeals $d o$ facilitate efficient targeting, they cannot also be inherently negative and of no benefit to anyone. Instead, their impact likely depends on the locus of evaluation: They may be a loss to the individual but still be socially beneficial.

The ordeal mechanism literature appears to have largely agreed to interpret ordeals to mean a direct cost placed upon an individual with the potential to more efficiently target collective resources and proceed accordingly, even as this is at odds with the standard definition of the concept. Hence, the debate within that literature centers on whether such frictions generate efficient targeting or not, rather than core definitional problems.

Less dramatically, we see contradictions between competing definitions of sludge. In one version, it is defined as a friction in a value free fashion (Sunstein, 2019), similar to administrative burden, allowing the possibility of both costly and beneficial sludge. In another version, it is "excessive" and "unjustified" (Sunstein, 2020) which moves it closer to the red tape and ordeals definition where sludge is inherently negative. This raises similar questions about the locus evaluation: is it still sludge if it serves a socially useful purpose? Given that sludge is the newest concept we consider, it may be that such contradictions will be soon resolved. But it also may be the case that multiple definitions emerge within sludge, as multiple scholars seek to elucidate the concept, similar to the evolution of the red tape concept.

Two competing impulses seem to be operating at the same time that give rise to the contradiction about whether frictions can have positive effects. On the one hand, declaring a friction to be unambiguously negative offers crisp conceptual clarity. On the other hand, such unambiguously negative frictions are hard to find. Most real-world examples are more complicated. They represent 
trade-offs, where costs sometimes outweigh benefits, and sometimes not; where rules will lack function for some purposes or groups but serve others. A definition that excludes frictions with some benefits - because they serve no purpose or do not benefit anyone - therefore also excludes the vast majority of frictions, even those where the net benefits are not justified. If the definition of a concept cannot survive contact with real-world examples, it has limited utility for applied scholarship.

Perhaps the general study of frictions could benefit from the less rigid stance on negativity of the administrative burden literature: what matters is not objective classifications of rules as frictions but the causes and - often more importantly - consequences of burdensome or onerous experiences among the objects of demands, requirements, rules, and practices. As we have noted above, it is possible to measure these experiences using both objective and subjective indicators. For example, Shahab and Lades (2020) propose that sludge be considered as a choice architecture that generates different types of costs, while Kaufmann and Haans (2020) call for red tape research to engage further with the role played by perceptions.

A second contradiction for red tape is between its focus on rules in classic definitions and its practical reliance on subjective measures of public managers and employees' experiences, which essentially place those individuals at the locus of evaluation. Administrative burden work has almost the opposite problem. By definition, administrative burden focus on experiences. Yet, much of the empirical work cited in the administrative burden literature, as in the sludge and ordeal mechanisms literature, strives to capture the objective effects of frictions on behavior despite the concept's definitional focus on the individual as the locus of evaluation. While objective measurement of outcomes has obvious benefits that all approaches could utilize, administrative burden researchers might look to red tape for development of standard instruments that capture individual experiences of compliance, learning, and psychological costs. 


\section{How are the Concepts Different?}

The previous sections outlined that, in many cases, differences in research custom perhaps overstate conceptual differences in the study of frictions, and differences between definitions and research practice suggest greater potential similarity than first observed. This does not mean that there are not real differences. We sketch out some of those here, while still seeking potential areas of mutual learning.

First, we see a clear and marked tension between the ordeals and administrative burden literatures in the degree to which frictions arise from differential utility models or differences in human capital, respectively. These assumptions matter in shaping expectations about whether frictions will facilitate efficient targeting or reinforce inequality. Even in cases where economists have found distributive effects of ordeals inverse to efficient targeting of resources, they have presented them as puzzles given the ordeal mechanism framework, rather than logical outcomes of human capital differences (Gupta, 2017). Deshpande and Li (2019, p. 214) offer the most direct criticism of ordeal mechanisms while working within that framework. They find that increasing compliance costs is especially damaging to those who needed services, such as those with moderately severe disabilities, low education, and low income. The ordeals therefore "exacerbate the very inequality that disability programs are intended to reduce" (Deshpande \& Li, 2019, p. 4) and generate social costs far in excess of whatever social benefits arise from rationing. By contrast, such an outcome is entirely predictable from an administrative burden framework (Christensen et al. 2020). At the same time, the administrative burden emphasis on human capital, and warning that political principals will target frictions for non-efficiency reasons creates a blind spot to the potential for efficient targeting. 
Second, a real definitional difference is that administrative burden frames individual experiences of frictions to be a burden, regardless of whether it is justified or not. As noted above, other research approaches might relax the definitional assumption that red tape is without offsetting benefits, ordeals is a deadweight loss, or sludge is excessive in practice. Allowing positive benefits of frictions has the value of opening the possibility for the experience of frictions, even onerous and frustrating ones, to be usefully deployed in solving policy problems. An example comes from Alpert et al. (2019), who show that US states that required more compliance costs for doctors in prescribing opioids experienced many fewer overdose deaths during the opioid crisis than states that made prescriptions easier. This example is intriguing not least since the benefits of the increased compliance cost are not simply social - though they are that - but individual. It would seem, then, that social gains are not the sole viable justification for burdensome rules and requirements.

\section{Conclusion}

Citizens and employees regularly experience frictions in their encounters with public sector organizations. This article has summarized basic overlaps and differences between concepts that address such frictions. In response to our initial question - are these all really the same thing - the answer is no. There are substantive differences between concepts, and in practice research traditions further exaggerate those differences. Part of the goal of this paper is to emphasize potential, as yet largely unrealized, connections and lessons sharing. For instance, we have highlighted the advancements in subjective measurements of red tape; the potential for sorting according to need as a social benefit of ordeal mechanisms; the utility of a steadfast individual locus of evaluation in the administrative burden; and a domain of application beyond the public sector in sludge. 
While our primary focus has been on building shared research agendas, we conclude with a practical note. Much of the recent interest in frictions is motivated by the normative agreement to find and reduce such frictions where their benefits cannot be justified. A consistent theme across the red tape (Bozeman, 2000), administrative burden (Herd \& Moynihan, 2018) and sludge (Sunstein, 2019) literatures is that organizations should do more to identify and reduce frictions. Such a goal presupposes a conceptualization flexible enough to acknowledge that many frictions a) have benefits, and b) it should be possible to weigh the relative benefits and costs. This, in turn, requires more detailed attention to the types of costs that people face, and their consequences.

A strength of administrative burden is its broadly applicable typology of costs. Indeed, Shahab and Lades (2020) recently urge a similar approach for sludge. The ability to develop general approaches to identifying the costs of friction is useful for three reasons. First, demarcating costs illustrate the nature of frictions, from an abstract to a more identifiable concept. Second, they offer communicative benefits - they show how specific types of frictions across different policy areas are part of the same broader phenomena. Of course, all concepts discussed perform this task to some extent, but a more specific consideration of types of costs deepens the potential to speak broadly of the role of the state. This could, for example, help illustrate how the psychological costs experienced by the person trying to vote, receive an abortion, apply for benefits, or start a business are related to one another. Third, demarcating costs provide a diagnostic tool. Conceptualizing specific types of frictions makes it easier to identify when they arise, and the nature of their effects. Rather than say "we need to cut ordeals" we can say, for example, "the main bottleneck is the compliance costs." For researchers, these distinctions are important in terms of creating expectations about how frictions will reveal themselves. For example, much of the red tape literature focuses on compliance costs (e.g. Coursey \& Pandey, 2007), neglecting learning and psychological costs. Of late, there is more attention to the latter. For instance, authors have invoked self-determination theory to argue that lack of functionality 
implied by red tape is costly to experienced basic human needs satisfaction (i.e. to relatedness, competence, or autonomy) (e.g. van Loon, 2017).

Ultimately, how people use these concepts may reflect factors other than those discussed here, such as disciplinary preferences, and dissemination of ideas within fields. Our hope is that researchers will be at least cognizant of different frameworks and the substantive differences they imply. In the interests of mutual learning, we have perhaps overemphasized potential areas of overlap, and understated what we have described as research customs that serve to maintain separate communities. Such customs reflect well-worn preferences and assumptions about what research is important and valid, and may be resistant to change. Researchers may be told that their particular approach to frictions is inadequate because it does not align with one or more of the concepts described here. But even path dependent research streams are occasionally punctuated by moments of paradigmatic change before resetting themselves. The study of frictions appears to be experiencing such a moment, driven by the arrival of new concepts, new scholarly interest, and a practical interest in applied solutions to public service problems. Our hope is that our effort to outline potential areas of overlap emphasizes how some of differences between these streams are artificial, and that we need active efforts to communicate across different approaches (e.g. Carrigan, Pandey, \& van Ryzin, 2020). The topic is large enough to allow multiple camps that can work together rather than ignore, or worse, bicker with each another with few to no offsetting benefits.

\section{References}

Alpert, A., Evans, W., Lieber, E., \& Powell, D. (2019). Origins of the Opioid Crisis and Its Enduring Impacts. (NBER Working Paper no. 26500). National Bureau of Economics Research. 
Alatas, V., Banerjee, A., Hanna, R., Olken, B., Purnamasari, R., \& Wai-Poi, M. (2016). SelfTargeting: Evidence from a Field Experiment in Indonesia. Journal of Political Economy, 124(2), $371-427$.

Barnes, C., \& Henly, J. (2018). They are underpaid and understaffed: How clients interpret encounters with street-level bureaucrats. Journal of Public Administration Research and Theory 28(2), 165-181.

Baekgaard, M., Moynihan, D. P. \& Thomsen, M. K. (In Press). Why Do Policymakers Support Administrative Burdens? The Roles of Deservingness, Political Ideology and Personal Experience. Journal of Public Administration Research and Theory.

Bozeman, B. (1993). A Theory of Government Red Tape. Journal of Public Administration Research and Theory 3(3), 273-303.

Bozeman, B. (2000). Bureaucracy and red tape. Upper Saddle River, NJ: Prentice Hall.

Bozeman, B. (2012). Multidimensional red tape: A theory coda. International Public Management Journal, 15(3), 245-265.

Bozeman, B., \& Anderson, D. (2016). Public Policy and the Origins of Bureaucratic Red Tape: Implications of the Stanford Yacht Scandal. Administration \& Society, 48(6), 736-759.

Bozeman, B., \& Feeney, M. (2011). Rules and Red Tape: A Prism for Public Administration Theory and Research: A Prism for Public Administration Theory and Research. Armonk, NY: M. E. Sharpe.

Bozeman, B., \& Scott, P. (1996). Bureaucratic red tape and formalization: Untangling conceptual knots. The American Review of Public Administration, 26(1), 1-17.

Brewer, G., \& Walker, R. (2010). Explaining Variation in Perceptions of Red Tape: A Professionalism-Marketization Model. Public Administration 88, 418-438

Burden, B., Canon, D., Mayer, K., \& Moynihan, D. (2012). The effect of administrative burden on bureaucratic perception of policies: Evidence from election administration. Public Administration Review, 72(5), 741-751.

Braconnier, C., Dormagen, J. \& Pons, V. (2017). Voter registration costs and disenfranchisement: experimental evidence from France. American Political Science Review 111(3), 584-604.

Carrigan, C, Sanjay K., \& Van Ryzin, G. (2020). Pursuing Consilience: Using Behavioral Public Administration to Connect Research on Bureaucratic Red Tape, Administrative Burden, and Regulation. Public Administration Review 80(1), 46-52.

Carter, D, Scott, T. \& Mahallati, N. (2018). Balancing Barriers to Entry and Administrative Burden in Voluntary Regulation. Perspectives on Public Management and Governance 1(3), 207-221.

Christensen, J., Aarøe, L., Baekgaard, M., Herd, P., \& Moynihan, D. (2020). Human Capital and Administrative Burden: The Role of Cognitive Resources in Citizen-State Interactions. Public Administration Review, 80(1), 127-136. 
Coursey, D. \& Pandey, S. (2007). Content Domain, Measurement, and Validity of the Red Tape Concept: A Second-Order Confirmatory Factor Analysis. American Review of Public Administration 37(3), 342-356.

De Jong, G. \& Witteloostuijn, A. (2015). Regulatory red tape and private firm performance. Public Administration, 93(1), 34-51.

Deshpande, M., \& Li, Y. (2019). Who Is Screened Out? Application Costs and the Targeting of Disability Programs. American Economic Journal: Economic Policy, 11(4), 213-48.

Feeney, M. \& Bozeman, B. (2009). Stakeholder Red Tape: Comparing Perceptions of Public Managers and Their Private Consultants. Public Administration Review 69(4), 710-726.

Feeney, M., \& Rainey, H. (2009). Personnel flexibility and red tape in public and nonprofit organizations: Distinctions due to institutional and political accountability. Journal of Public Administration Research and Theory, 20(4), 801-826.

Gupta, S. (2017). Perils of the Paperwork: The Impact of Information and Application Assistance on Welfare Program Take-Up in India. (Working paper). Harvard University Kennedy School of Government.

Hattke, F., Hensel, D., \& Kalucza, J. (2020) Emotional Responses to Bureaucratic Red Tape. Public Administration Review, 80(1), 53-63

Heinrich, C. (2016). The bite of administrative burden: A theoretical and empirical investigation. Journal of Public Administration Research and Theory, 26(3), 403-420.

Heinrich, C. (2018). Presidential address: "A thousand petty fortresses": Administrative burden in US immigration policies and its consequences. Journal of Policy Analysis and Management, 37(2), 211-239.

Herd, P., DeLeire, T., Harvey, H., \& Moynihan, D. (2013). Shifting administrative burden to the state: The case of Medicaid Take-Up. Public Administration Review, 73(1), 69-S81.

Herd, P. \& Moynihan, D. (2018). Administrative burden: Policymaking by other means. New York: Russell Sage Foundation.

Jilke, S., Van Dooren, W., \& Rys, S. (2018). Discrimination and administrative burden in public service markets: Does a public-private difference exist? Journal of Public Administration Research and Theory, 28(3), 423-439.

Kaufman, H. (1977). Red Tape, Its Origins, Uses, and Abuses. Washington, DC: Brookings Institution Press.

Kaufmann, W. \& Feeney, M. (2012). Objective formalization, perceived formalization, and perceived red tape. Public Management Review, 14, 1195-1214. 
Kaufmann, W. \& Feeney, M. (2014). Beyond the rules: The effect of outcome favourability on red tape perceptions. Public Administration, 92, 178-191.

Kaufmann, W. \& Tummers, L. (2017). The negative effect of red tape on procedural satisfaction. Public Management Review, 19, 1311-1327.

Kaufmann, W, Hooghiemstra, R., \& Feeney, M. (2018). Formal institutions, informal institutions, and red tape: A comparative study. Public Administration, 96(2), 386-403.

Kaufmann, W., Borry, E., \& DeHart-Davis, L. (2019). More than Pathological Formalization: Understanding Organizational Structure and Red Tape. Public Administration Review, 79(2), 236245.

Kaufmann, W., \& Haans, R. (2020). Understanding the meaning of concepts across domains through collocation analysis: An application to the study of red tape. Journal of Public Administration Research and Theory, 1-16.

Lavertu, S., Lewis, D. \& Moynihan, D. (2013). Government reform, political ideology, and administrative burden: The case of performance management in the Bush administration. Public Administration Review, 73(6), 845-857.

Linos, E., \& Riesch, N. (2020). Thick Red Tape and the Thin Blue Line: A Field Study on Reducing Administrative Burden in Police Recruitment. Public Administration Review, 80(1), 92-103.

Moynihan, D., Herd, P. \& Harvey, H. (2014). Administrative burden: Learning, psychological, and compliance costs in citizen-state interactions. Journal of Public Administration Research and Theory, 25(1), 43-69.

Moynihan, D. \& Herd, P. (2010). Red Tape and Democracy: How Rules Affect Citizenship Rights. The American Review of Public Administration, 40(6), 654-670.

Moynihan, D., Herd, P. \& Ribgy, E. (2016) Policymaking by Other Means: Do States Use Administrative Barriers to Limit Access to Medicaid? Administration \& Society, 48(4), 497-524

Nichols, A., \& Zeckhauser, R. (1982). Targeting Transfers through Restrictions on Recipients. American Economic Review, 72(2), 372-77.

Nisar, M. (2018). Children of a lesser god: Administrative burden and social equity in citizen-state interactions. Journal of Public Administration Research and Theory, 28(1), 104-119.

Pandey, S., Coursey, D., \& Moynihan, D. (2007). Organizational Effectiveness and Bureaucratic Red Tape: A Multimethod Study. Public Performance and Management Review, 30(3), 398-425.

Pandey, S. \& Kingsley, G. (2000). Examining Red Tape in Public and Private Organizations. Journal of Public Administration Research and Theory, 10(4), 779-799.

Pandey, S. \& Scott, P. (2002). Red Tape: A Review and Assessment of Concepts and Measures. Journal of Public Administration Research and Theory, 12(4), 553-580. 
Peeters, R. (2020). The political economy of administrative burdens: A theoretical framework for analyzing the organizational origins of administrative burdens. Administration \& Society, 52(4), 566-592.

Peeters, R. \& Widlak, A. (2018). The digital cage: Administrative exclusion through information architecture-The case of the Dutch civil registry's master data management system. Government Information Quarterly, 35(2), 175-183.

Steijn, B. \& van der Voet, J. (2019). Relational job characteristics and job satisfaction of public sector employees: When prosocial motivation and red tape collide. Public Administration, 97(1), 64-80

Sunstein, C. (2019). Sludge and Ordeals. Duke Law Journal 68, 1843-883

Sunstein, C. (2020). Sludge Audits. Behavioural Public Policy: 1-20. doi:10.1017/bpp.2019.32

Thaler, R. (2018). Nudge, Not Sludge. Science, 361(6401), 431.

Tummers, L. Weske, U., Bouwman, R., \& Grimmelikhuijsen, S. (2016) The Impact of Red Tape on Citizen Satisfaction: An Experimental Study. International Public Management Journal, 19(3), 320341.

Van Loon, N., Leisink, P., Knies, E. \& Brewer, G. (2016). Red tape: Developing and validating a new job-centered measure. Public Administration Review, 76(4), 662-673.

Van Loon, N. (2017). From red tape to which performance results? Exploring the relationship between red tape and various dimensions of performance in healthcare work units. Public Administration, 95(1), 60-77.

Yasenov, V., Hotard, M., Lawrence, D. Hainmueller, J. \& Laitin, D. (2019). Standardizing the feewaiver application increased naturalization rates of low-income immigrants. Proceedings of the National Academy of Sciences, 116(34), 16768-16772.

Zeckhauser, R. (2019). Strategic Sorting: The Role of Ordeals in Health Care. (Working Paper no. 26041). National Bureau of Economic Research. 
Table 1: Definitions

\begin{tabular}{|c|c|c|}
\hline Concept & Definition Label & Definition \\
\hline \multirow[t]{3}{*}{$\begin{array}{l}\text { Administrative } \\
\text { burden }\end{array}$} & Experience & $\begin{array}{l}\text { "[A]n individual's experience of a policy's implementation as } \\
\text { onerous" (Burden et al., 2012, p. 741; Herd \& Moynihan, 2018, p. } \\
\text { 22). }\end{array}$ \\
\hline & Imposition & \\
\hline & & $\begin{array}{l}\text { "[I]nteractions with government that impose (or lessen) burdens on } \\
\text { individuals and organizations" (Heinrich, 2018, p. 216) }\end{array}$ \\
\hline Ordeal mechanisms & Ordeals & $\begin{array}{l}\text { "[T] he imposition of deadweight costs to qualify for a transfer" } \\
\text { (Nichols \& Zeckhauser, 1982, p. 372); "burdens placed on } \\
\text { individuals that yield no direct benefits to others" (Zeckhauser, 2019, } \\
\text { p. 2). }\end{array}$ \\
\hline \multirow[t]{4}{*}{ Red tape } & Legitimate purposes & $\begin{array}{l}\text { "[R]ules, regulations and procedures that entail a compliance burden } \\
\text { without advancing the legitimate purposes they were intended to } \\
\text { serve" (Bozeman, 2000, p. 12) }\end{array}$ \\
\hline & Organizational & $\begin{array}{l}\text { "[R]ules, regulations and procedures that remain in force and entail } \\
\text { a compliance burden for the organization but have no efficacy for the } \\
\text { rules' functional object' (Bozeman, 1993, p. 283) }\end{array}$ \\
\hline & Stakeholder & $\begin{array}{l}\text { "[R]ules, regulations, and procedures that remain in force and entail } \\
\text { a compliance burden, but serve no objective valued by a given } \\
\text { stakeholder group" (Bozeman, 1993, p. 284) }\end{array}$ \\
\hline & Impressions & $\begin{array}{l}\text { "[I]mpressions on the part of managers that formalization (in the } \\
\text { form of burdensome rules and regulations) is detrimental to the } \\
\text { organization." (Pandey \& Kingsley, 2000, p. 782) }\end{array}$ \\
\hline \multirow[t]{2}{*}{ Sludge } & Direction-frustrating & $\begin{array}{l}\text { "T]he kind of friction, large or small, that people face when they want } \\
\text { to go in one or another direction" (Sunstein, 2019, p. 1850); }\end{array}$ \\
\hline & Goal-frustrating & $\begin{array}{l}\text { "EJxcessive or unjustified frictions that make it more difficult for } \\
\text { consumers, employees, employers, students, patients, clients, small } \\
\text { businesses, and many others to get what they want or to do as they } \\
\text { wish" (Sunstein, 2020, p. } 3 \text { paraphrasing Thaler, 2018). }\end{array}$ \\
\hline
\end{tabular}


Table 2: Concepts and parameters

\begin{tabular}{lllll}
\hline & Objectivity & Distributiveness & Object and Domain & Intentionality \\
\hline $\begin{array}{l}\text { Administrative } \\
\text { burden }\end{array}$ & $\begin{array}{l}\text { Experienced, often } \\
\text { captured via } \\
\text { objective changes in } \\
\text { frictions }\end{array}$ & $\begin{array}{l}\text { Frictions worsen } \\
\text { inequality }\end{array}$ & $\begin{array}{l}\text { Largely citizens, } \\
\text { sometimes employees, } \\
\text { public services }\end{array}$ & $\begin{array}{l}\text { Yes }- \\
\text { policymaking by } \\
\text { other means }\end{array}$ \\
\hline $\begin{array}{l}\text { Ordeal } \\
\text { mechanisms }\end{array}$ & $\begin{array}{l}\text { Objective changes } \\
\text { in frictions }\end{array}$ & $\begin{array}{l}\text { Frictions can } \\
\text { minimize } \\
\text { inequality }\end{array}$ & $\begin{array}{l}\text { Largely citizens, } \\
\text { public services }\end{array}$ & $\begin{array}{l}\text { Yes - as a means } \\
\text { of targeting }\end{array}$ \\
\hline Red tape & $\begin{array}{l}\text { Objective in } \\
\text { common } \\
\text { definitions, } \\
\text { typically captured } \\
\text { via perceptions }\end{array}$ & Rarely considered & $\begin{array}{l}\text { Largely } \\
\text { employees/managers, } \\
\text { sometimes citizens, } \\
\text { public services }\end{array}$ & $\begin{array}{l}\text { Limited - related } \\
\text { to publicness }\end{array}$ \\
\hline & $\begin{array}{l}\text { Objective changes } \\
\text { in frictions }\end{array}$ & $\begin{array}{l}\text { Frictions worsen } \\
\text { inequality }\end{array}$ & $\begin{array}{l}\text { Citizens and } \\
\text { customers, public and } \\
\text { private }\end{array}$ & Possible \\
\hline
\end{tabular}




\section{Appendix: Burdens, Sludge, Ordeals, Red Tape, Oh My!}

As noted in the article, we systematically searched the literatures on red tape and administrative burden to ensure broad coverage for our discussion of the terms originating in public administration scholarship. Due to the uneven age of the two literatures - the literature on red tape in its current form is decades older than the administrative burden literature in its current form - we opted for slightly different strategies for the two concepts.

For red tape, exhaustive reviews exist but are somewhat dated. In particular, Bozeman and Feeney survey "the entire" red tape literature (2011). Hence, good overviews of the literature from which we can glean important works already exist. We did update the 2011 overview by searching journal articles with the term "red tape" in the title or abstract from 2012 to 2020 across five journals: Journal of Public Administration Research and Theory, Public Administration Review, Public Administration, Governance, and Public Management Review. As shown below, this search yielded 26 additional publications since Bozeman and Feeney (2011).

We performed the same search for "administrative burden" in abstracts across the same five journals. However, this strategy did not yield as many results. As no overview of the administrative burden literature comparable to Bozeman and Feeney's (2011) book exists, we widened our search for administrative burden publications. In particular, we performed a Google Scholar search for published, English language articles referencing either (1) Burden et al.'s (2012) initial work introducing "administrative burden" as a concept, (2) Moynihan et al.'s (2014) article outlining the three fundamental costs of administrative burden (compliance, learning, and psychological, see the paper for a discussion), or (3) Herd and Moynihan's (2018) book on the administrative burdens as policy by other means. These three works are selected for their foundational role in the current administrative burden literature and expanded our list of administrative burden literature to a total of 48 published articles. Note that, due to differences in search strategy, this number does not necessarily indicate that administrative burden is a more popular term than red tape in public administration research.

As noted in the article, some scholars use the two terms interchangeably. As a result, three entries from a special issue in Public Administration Review on burdens and red tape appear in both lists (Bozeman and Youtie 2020; Carrigan et al. 2020; Linos \& Riesch 2020). 


\section{Red tape}

Bozeman, B., \& Youtie, J. (2020). Robotic bureaucracy: Administrative burden and red tape in university research. Public Administration Review, 80(1), 157-162.*

Carrigan, C., Pandey, S. K., \& Van Ryzin, G. G. (2020). "Pursuing Consilience: Using Behavioral Public Administration to Connect Research on Bureaucratic Red Tape, Administrative Burden, and Regulation." Public Administration Review, 80(1), 46-52.*

Chen, C. A., \& Rainey, H. G. (2014). Personnel Formalization and the Enhancement Of Teamwork: A public-private comparison. Public Management Review, 16(7), 945-968.

Davis, R. S. (2013). Unionization and work attitudes: How union commitment influences public sector job satisfaction. Public Administration Review, 73(1), 74-84.

De Jong, G., \& Van Witteloostuijn, A. (2015). Regulatory red tape and private firm performance. Public Administration, 93(1), 34-51.

Feeney, M. K. (2012). Organizational red tape: A measurement experiment. Journal of Public Administration Research and Theory, 22(3), 427-444.

Hattke, F., Vogel, R., \& Znanewitz, J. (2018). Satisfied with red tape? Leadership, civic duty, and career intention in the military. Public Management Review, 20(4), 563-586.

Hattke, F., Hensel, D., \& Kalucza, J. (2020). Emotional responses to bureaucratic red tape. Public Administration Review, 80(1), 53-63.

Hong, S. (In Press). "Performance Management Meets Red Tape: Bounded Rationality, Negativity Bias, and Resource Dependence." Public Administration Review.

Homberg, F., Vogel, R., \& Weiherl, J. (2019). Public service motivation and continuous organizational change: Taking charge behaviour at police services. Public Administration, 97(1), 28-47.

Jacobsen, C. B., \& Jakobsen, M. L. (2018). Perceived organizational red tape and organizational performance in public services. Public Administration Review, 78(1), 24-36.

Jung, C. S., \& Kim, S. E. (2014). Structure and perceived performance in public organizations. Public Management Review, 16(5), 620-642.

Kaufmann, W., Borry, E. L., \& DeHart-Davis, L. (2019). More than pathological formalization: Understanding organizational structure and red tape. Public Administration Review, 79(2), 236-245.

Kaufmann, W., Hooghiemstra, R., \& Feeney, M. K. (2018). Formal institutions, informal institutions, and red tape: A comparative study. Public Administration, 96(2), 386-403.

Kaufmann, W., \& Feeney, M. K. (2014). Beyond the rules: The effect of outcome favourability on red tape perceptions. Public Administration, 92(1), 178-191.

Kaufmann, W., \& Feeney, M. K. (2012). Objective formalization, perceived formalization and perceived red tape: Sorting out concepts. Public Management Review, 14(8), 11951214. 
Kaufmann, W., \& Tummers, L. (2017). The negative effect of red tape on procedural satisfaction. Public Management Review, 19(9), 1311-1327.

Kaufmann, W., \& Haans, R. (In Press). Understanding the Meaning of Concepts Across Domains Through Collocation Analysis. Journal of Public Administration Research and Theory.

Linos, E., \& Riesch, N. (2020). Thick Red Tape and the Thin Blue Line: A Field Study on Reducing Administrative Burden in Police Recruitment. Public Administration Review, 80(1), 92-103.*

Moynihan, D. P. (2012). A theory of culture-switching: Leadership and red-tape during hurricane Katrina. Public Administration, 90(4), 851-868.

Riccucci, N. M. (2012). Reconceptualizing Red Tape Research. Public Administration Review, 72(3), 463-465.

Steijn, B., \& van der Voet, J. (2019). Relational job characteristics and job satisfaction of public sector employees: When prosocial motivation and red tape collide. Public Administration, 97(1), 64-80.

Torenvlied, R., \& Akkerman, A. (2012). Effects of managers' work motivation and networking activity on their reported levels of external red tape. Journal of Public Administration Research and Theory, 22(3), 445-471.

Van Loon, N. M., Leisink, P. L., Knies, E., \& Brewer, G. A. (2016). Red tape: Developing and validating a new job-centered measure. Public Administration Review, 76(4), 662-673.

Van Loon, N. M. (2017). From red tape to which performance results? Exploring the relationship between red tape and various dimensions of performance in healthcare work units. Public Administration, 95(1), 60-77.

Vinarski Peretz, H. (2020). A view into managers' subjective experiences of public service motivation and work engagement: a qualitative study. Public Management Review, 22(7), 1090-1118.

\section{Administrative burden}

Baekgaard, M., Moynihan, D. P., \& Thomsen, M. K. (In Press). Why Do Policymakers Support Administrative Burdens? The Roles of Deservingness, Political Ideology, and Personal Experience. Journal of Public Administration Research and Theory.

Barnes, C. Y. (In Press). "It takes a while to get used to": The Costs of Redeeming Public Benefits. Journal of Public Administration Research and Theory.

Barnes, C. Y., \& Henly, J. R. (2018). "They are underpaid and understaffed": How clients interpret encounters with street-level bureaucrats. Journal of Public Administration Research and Theory, 28(2), 165-181. 
Bashir, M., \& Nisar, M. A. (2020). Expectation versus Reality: Political Expediency and Implementation of Right to Information Laws. Public Administration Quarterly, 44(1).

Bell, E., Ter Mkrtchyan, A., Wehde, W., \& Smith, K. (In Press). Just or Unjust? How Ideological Beliefs Shape Street-level Bureaucrats' Perceptions of Administrative Burden. Public Administration Review.

Bozeman, B., \& Youtie, J. (2020). Robotic bureaucracy: Administrative burden and red tape in university research. Public Administration Review, 80(1), 157-162.*

Bozeman, B., Youtie, J., \& Jung, J. (In Press (a)). Robotic Bureaucracy and Administrative Burden: What Are the Effects of Universities' Computer Automated Research Grants Management Systems?. Research Policy, 49(6).

Bozeman, B., Youtie, J., \& Jung, J. (In Press (b)). Death by a Thousand 10-Minute Tasks: Workarounds and Noncompliance in University Research Administration. Administration \& Society.

Burden, B. C., Canon, D. T., Mayer, K. R., \& Moynihan, D. P. (2012). The effect of administrative burden on bureaucratic perception of policies: Evidence from election administration. Public Administration Review, 72(5), 741-751.

Carrigan, C., Pandey, S. K., \& Van Ryzin, G. G. (2020). Pursuing Consilience: Using Behavioral Public Administration to Connect Research on Bureaucratic Red Tape, Administrative Burden, and Regulation. Public Administration Review, 80(1), 46-52.*

Carter, D. P., Scott, T. A., \& Mahallati, N. (2017). Balancing barriers to entry and administrative burden in voluntary regulation. Perspectives on Public Management and Governance, 1(3), 207-221.

Christensen, J., Aarøe, L., Baekgaard, M., Herd, P., \& Moynihan, D. P. (2020). Human Capital and Administrative Burden: The Role of Cognitive Resources in Citizen-State Interactions. Public Administration Review, 80(1), 127-136.

Chudnovsky, M., \& Peeters, R. (2020). The unequal distribution of administrative burden: A framework and an illustrative case study for understanding variation in people's experience of burdens. Social Policy \& Administration.

Daigneault, P. M., \& Macé, C. (2020). Program awareness, administrative burden, and nontake-up of Québec's Supplement to the Work Premium. International Journal of Public Administration, 43(6), 527-539.

Doughty, M., \& Baehler, K. J. (2020). "Hostages to Compliance": Towards a Reasonableness Test for Administrative Burdens. Perspectives on Public Management and Governance.

Fox, A. M., Stazyk, E. C., \& Feng, W. (2020). Administrative Easing: Rule Reduction and Medicaid Enrollment. Public Administration Review, 80(1), 104-117.

Hartlapp, M., \& Heidbreder, E. G. (2018). Mending the hole in multilevel implementation: Administrative cooperation related to worker mobility. Governance, 31(1), 27-43. 
Heflin, C. M., Lopoo, L. M., \& Mackenzie-Liu, M. (2020) When States Align Social Welfare Programs: Considering the Child Support Income Exclusion for SNAP. Social Science Quarterly.

Heinrich, C. J. (2015). The bite of administrative burden: A theoretical and empirical investigation. Journal of Public Administration Research and Theory, 26(3), 403-420.

Heinrich, C. J. (2018). Presidential address: "A thousand petty fortresses": Administrative burden in US immigration policies and its consequences. Journal of Policy Analysis and Management, 37(2), 211-239.

Herd, P. (2015). How administrative burdens are preventing access to critical income supports for older adults: the case of the Supplemental Nutrition Assistance Program. Public Policy \& Aging Report, 25(2), 52-55.

Herd, P., DeLeire, T., Harvey, H., \& Moynihan, D. P. (2013). Shifting administrative burden to the state: The case of medicaid take-up. Public Administration Review, 73(1), 69-81.

Herd, P., \& Moynihan, D. P. (2018). Administrative burden: Policymaking by other means. Russell Sage Foundation.

Herd, P., \& Moynihan, D. (2020). Administrative Burdens in Health Policy. Journal of Health \& Human Services Administration, 43(1), 3-16

Jilke, S., Van Dooren, W., \& Rys, S. (2018). Discrimination and administrative burden in public service markets: Does a public-private difference exist? Journal of Public Administration Research and Theory, 28(3), 423-439.

Kaufmann, W., Ingrams, A., \& Jacobs, D. (In Press). Being Consistent Matters: Experimental Evidence on the Effect of Rule Consistency on Citizen Red Tape. The American Review of Public Administration.

Keiser, L. R., \& Miller, S. M. (2020). Does Administrative Burden Influence Public Support for Government Programs? Evidence from a Survey Experiment. Public Administration Review, 80(1), 137-150.

Lavertu, S., Lewis, D. E., \& Moynihan, D. P. (2013). Government reform, political ideology, and administrative burden: The case of performance management in the Bush administration. Public Administration Review, 73(6), 845-857.

Linos, E., \& Riesch, N. (2020). Thick Red Tape and the Thin Blue Line: A Field Study on Reducing Administrative Burden in Police Recruitment. Public Administration Review, 80(1), 92-103.*

Linos, E., Quan, L. T., \& Kirkman, E. (2020). Nudging Early Reduces Administrative Burden: Three Field Experiments to Improve Code Enforcement. Journal of Policy Analysis and Management, 39(1), 243-265.

Lopoo, L. M., Heflin, C., \& Boskovski, J. (2020). Testing behavioral interventions designed to improve on-time SNAP recertification. Journal of Behavioral Public Administration, 3(2). 
Masood, A., \& Nisar, M. A. (In Press). Administrative Capital and Citizens' Responses to Administrative Burden. Journal of Public Administration Research and Theory.

Masood, A., \& Nisar, M. A. (In Press (b)). Crushed between two stones: Competing institutional logics in the implementation of maternity leave policies in Pakistan. Gender, Work \& Organization.

Moynihan, D., Herd, P., \& Harvey, H. (2014). Administrative burden: Learning, psychological, and compliance costs in citizen-state interactions. Journal of Public Administration Research and Theory, 25(1), 43-69.

Moynihan, D. P., Herd, P., \& Ribgy, E. (2016). Policymaking by other means: Do states use administrative barriers to limit access to Medicaid? Administration \& Society, 48(4), 497524.

Nisar, M. A. (2017). Children of a lesser god: Administrative burden and social equity in citizen-state interactions. Journal of Public Administration Research and Theory, 28(1), 104-119.

Ntaliani, M., \& Costopoulou, C. (2018). E-Government for Lowering Administrative Burden: An Empirical Research on European Rural Businesses. International Journal of Public Administration, 41(9), 700-711.

Peeters, R., \& Widlak, A. (2018). The digital cage: Administrative exclusion through information architecture-The case of the Dutch civil registry's master data management system. Government Information Quarterly, 35(2), 175-183.

Peeters, R., Trujillo Jimenez, H., O'Connor, E., Ogarrio Rojas, P., Gonzalez Galindo, M., \& Morales Tenorio, D. (2018). Low-trust bureaucracy: Understanding the Mexican bureaucratic experience. Public Administration and Development, 38(2), 65-74.

Peeters, R. (2019). The Political Economy of Administrative Burdens: A Theoretical Framework for Analyzing the Organizational Origins of Administrative Burdens. Administration \& Society.

Rinehart, C. S., \& McGuire, J. W. (2017). Obstacles to Takeup: Ecuador's Conditional Cash Transfer Program, The Bono de Desarrollo Humano. World Development, 97, 165-177.

Selin, J. L. (2019). The Best Laid Plans: How Administrative Burden Complicates Voting Rights Restoration Law and Policy. Missouri Law Review, 84.

Sievert, M., Vogel, D., \& Feeney, M. K. (In Press). Formalization and administrative burden as obstacles to employee recruitment: Consequences for the public sector. Review of Public Personnel Administration.

Stanica, C. M., Balica, D., Henderson, A. C., \& Țiclău, T. C. (2020). The weight of service delivery: administrative and rules burdens in street-level bureaucracy. International Review of Administrative Sciences.

Thomsen, M. K., Bækgaard, M., \& Jensen, U. T. (2020). The Psychological Costs of Citizen Coproduction. Journal of Public Administration Research and Theory, 30(4), 656-673 
Weaver, R. K. (2015). Getting people to behave: Research lessons for policy makers. Public Administration Review, 75(6), 806-816.

Widlak, A., \& Peeters, R. (2020). Administrative errors and the burden of correction and consequence: how information technology exacerbates the consequences of bureaucratic mistakes for citizens. International Journal of Electronic Governance, 12(1), 40-56.

Wiley, K., \& Berry, F. (2018). Compassionate Bureaucracy: Assuming the Administrative Burden of Policy Implementation. Nonprofit and Voluntary Sector Quarterly, 47(4_suppl), 55S-75S. 